\title{
Accessibility of sports facilities for persons with reduced mobility and assessment of their motivation for practice
}

\author{
Maria Manuel Sáa, ${ }^{\mathrm{a}}$, Rui Azevedo ${ }^{\mathrm{b}}$, Maria Cristina Martins ${ }^{\mathrm{a}}$, Osvaldo Machado ${ }^{\mathrm{b}}$ and João Tavares ${ }^{\mathrm{b}}$ \\ ${ }^{a}$ CIDESD - ISMAI, Instituto Superior da Maia \\ ${ }^{b}$ CATST-ISMAI, Instituto Superior da Maia \\ Av. Carlos Oliveira Campos, Castêlo da Maia; 4475-690 Avioso S. Pedro, Portugal
}

\begin{abstract}
This study aims to create awareness, both within the scientific community and among providers of sports facilities, for individuals with impaired or reduced mobility, promoting the development of technical solutions that allow greater autonomy and social integration of people with disabilities. The purpose of this work is, on the one hand, to evaluate the accessibility of sports facilities for people with reduced mobility and, on the other hand, to investigate why this user group has such low rates of participation in sporting activities. Firstly, using the Portuguese norms and legislation transcribed from European Community directives, a check list was created comprising all the items that sports facilities should abide by in order to provide accessibility and safety to people with reduced mobility. Another questionnaire was designed aimed at this user group, with questions pertaining to their desire and ability to use sports facilities. This questionnaire was distributed in Portugal, in the greater metropolitan area of Porto, to users of Rehabilitation Centres and Physiotherapy Clinics. The results obtained from the check-list showed the compliances and non-compliances of the respective sports facilities, proving that many barriers preventing the participation of people with reduced mobility still exist. Twenty-four people with permanent impairment of the lower extremities (paraplegia) answered the questionnaire pertaining to the desire and ability to perform physical activity. Two individuals $(8 \%)$ had sporting activities available to them in their area of residence and only five $(21 \%)$ performed any physical activity. The main reason given for not taking part in any activity was the lack of adapted sports facilities. All the participants felt that taking part in sports is beneficial. The benefits stated were: general well-being and development of the psychomotor component (e.g. coordination, balance, body posture), of physical condition (e.g. strength, resistance, flexibility) and social integration and quality of life. Besides wellbeing, they also mentioned social interaction, a way of occupying their time and an escape from the routine as the main motives for which they would like to take up physical exercise.
\end{abstract}

Keywords: accessibility, safety, sports facilities, conditioned mobility

\section{Introduction}

Doing sports is seen as an important intervention instrument for persons with disabilities [1]. Sporting activities can be grouped into several strands, such as educational, recreational, professional, competitive and therapeutic, which also apply to persons with disabilities [2].

Approximately 38 million European citizens (one in ten) are disabled. The autonomy of a disabled person is not only determined by his/her physical condition, but also by the surrounding physical environ- ment [3]. Restricted mobility has been defined as the condition in which persons have some difficulty interacting with the surrounding environment, products, equipment or services due to the absence of mobility, orientation communication or achievement of information [4]. Therefore, according to these authors, every person has experienced some kind of mobility disability during their lifetime.

Doing sports is an invaluable instrument of intervention for disabled persons. On an individual level, sport can contribute to the improvement of the physical condition (e.g. increased strength, endurance,

\footnotetext{
* Corresponding author. E-mail: maria.sa@docentes.ismai.pt.
} 
flexibility), psychomotor development (improvement of postural control, motor coordination, balance), cognitive development, promoting a sense of wellbeing and balance, preventing states of depression, reducing irritability and aggressiveness [5]. On a social level, sport also fosters the integration of disabled people, by focusing on their abilities instead of on their difficulties.

The European Council's Sport for All Charter [6] recognises physical activity as "a valuable means of education, enhancement of recreation and social integration." The Portuguese Law no. 38/2004 of 18 August [7], which defines the basis for the legal state of Prevention, Empowerment, Participation and Rehabilitation of disabled persons, reinforces the value of sport for disabled citizens and places the onus of responsibility on the state to adopt the necessary measures to ensure the access of disabled people to sporting activities, including high-level competitive sports. Portuguese legislation makes it mandatory to adopt basic technical norms to eliminate architectural barriers in public buildings, community facilities and public roads to improve the accessibility of people with reduced mobility.

The work herein described aims to raise awareness in the scientific community of the needs of individuals with reduced mobility and to inform the authorities responsible for sports facilities, promoting the development of innovative and more suitable techniques and materials, in order to overcome any barriers experienced and foster social inclusion.

The purpose of this work is, on the one hand, to evaluate the accessibility of sports facilities for people with reduced mobility and, on the other hand, to investigate their motivations for participating in sporting activities.

\section{Method}

The methodology used in this study involved two stages. The first stage assessed the degree of compliance of the legal requirements by a group of sports facilities, by means of a check-list. In the second stage, a questionnaire was carried out among people with reduced mobility, with the goal of investigating their motivation for physical exercise.

Based on Portuguese and European norms and legislation, a checklist was created with all items that sports facilities should fulfil for the accessibility and safety of persons with reduced mobility. The checklist was divided into eleven sections: exterior access, ramps, stairs, interior access, lift, interior circulation, sanitary facilities (showers and changing rooms), electrical installation, sports equipment, swimming pools, and car parking spaces. Each of these sections comprises a set of accessibility items/technical norms that should be observed to ensure unrestricted access for people with reduced mobility. After careful observation, each item was labelled as compliant, not compliant, or not applicable depending on the case analysed. The study sample consisted of 11 public sports complexes/facilities of the greater metropolitan area of Porto, with authorisation from the city council.

The questionnaire for people with reduced mobility was divided into three parts: the first part pertained to the characteristics of the sample/personal data; the second part pertained to physical activity; and the third part pertained to motivation and benefits obtained from doing sport. This questionnaire was distributed to people with reduced mobility in the greater Porto area, contacted through Rehabilitation Centres and Physiotherapy Clinics.

\section{Results and discussion}

\subsection{Checklist for sports complexes/facilities}

This section presents the degree of compliance obtained in the various sections of the checklist, for all items/technical norms that promote accessibility for people with reduced mobility. The degree of conformity is calculated as a percentage, by dividing the number of compliant cases by the total number of cases, when applicable. The results presented highlight the items where the degree of compliance is lower.

\subsubsection{Buildings and establishments in general}

Figure 1 shows the level of compliance achieved for the building in general. It was found that $87.5 \%$ of the buildings have at least one accessible route that provides safe and comfortable access for people with reduced mobility, between the road and the main entrance/exit, and all their interior and exterior areas. Furthermore, in $87.5 \%$ of the cases, it is possible to perform a $360^{\circ}$ rotation in the inner atrium. In $75 \%$ of the cases there are specific manoeuvre areas that allow a $360^{\circ}$ rotation or to change the direction by $180^{\circ}$ in $\mathrm{T}$, a norm that should be observed when the width of landings, galleries or corridors is less than $1.5 \mathrm{me}-$ 
ters. None of the buildings' staircases had steps with non-slip strips and visual markers, with a distance of no less than 0.04 meters from the step nosing, and only $87.5 \%$ had a curvature radius of the step nosing between 0.005 and 0.01 meters. Only in $28.6 \%$ of cases in which the stairs bridged rises greater than $0.4 \mathrm{~m}$ were there handrails on both sides of the staircase.

At the top of the stairs, handrails should extend at least 0.3 meters beyond the last step, and handrails should extend beyond the first step in a length equal to the size of the tread of the step; the degree of compliance found for these two items was $50 \%$ and $0 \%$ respectively.

None of the ramps analysed had bands of different colour and texture which contrasted with the adjacent pavement, at the beginning and end of the ramp, and handrail on both sides, as required by regulatory documents. Only $28.6 \%$ of these ramps met the following conditions: slope not exceeding $6 \%$ for a rise of no more than 0.6 meters and length of more than 10 meters, or slope not exceeding $8 \%$ for a rise of less than 0.4 meters and length of no more than 5 meters. On the other hand, $66.7 \%$ of ramps and land- ings with a difference of over 0.1 meters in relation to adjacent levels and which bridge rises of over 0.3 meters are accompanied by a protection element (walls, partitions, lateral barriers ...) along the full length of the ramps.

In $63.5 \%$ of the buildings, there are significant level changes (bumps on the floor). This bump on the floor is also found in $75 \%$ of interior doors (raised runners, thresholds or sills).

Only $20 \%$ of passages between buildings were covered.

In terms of signs, there was signage only in $25 \%$ of cases to direct users to accessible entrances/exits, accessible routes, parking places for disabled visitors and accessible sanitary facilities for general use. When signage was present, in only $12.5 \%$ of the cases was it positioned in a way that it could be easily seen, read and understood by a standing or sitting user, and had characters and symbols with contrasting colours in relation to the background, enabling a clear understanding of the message.

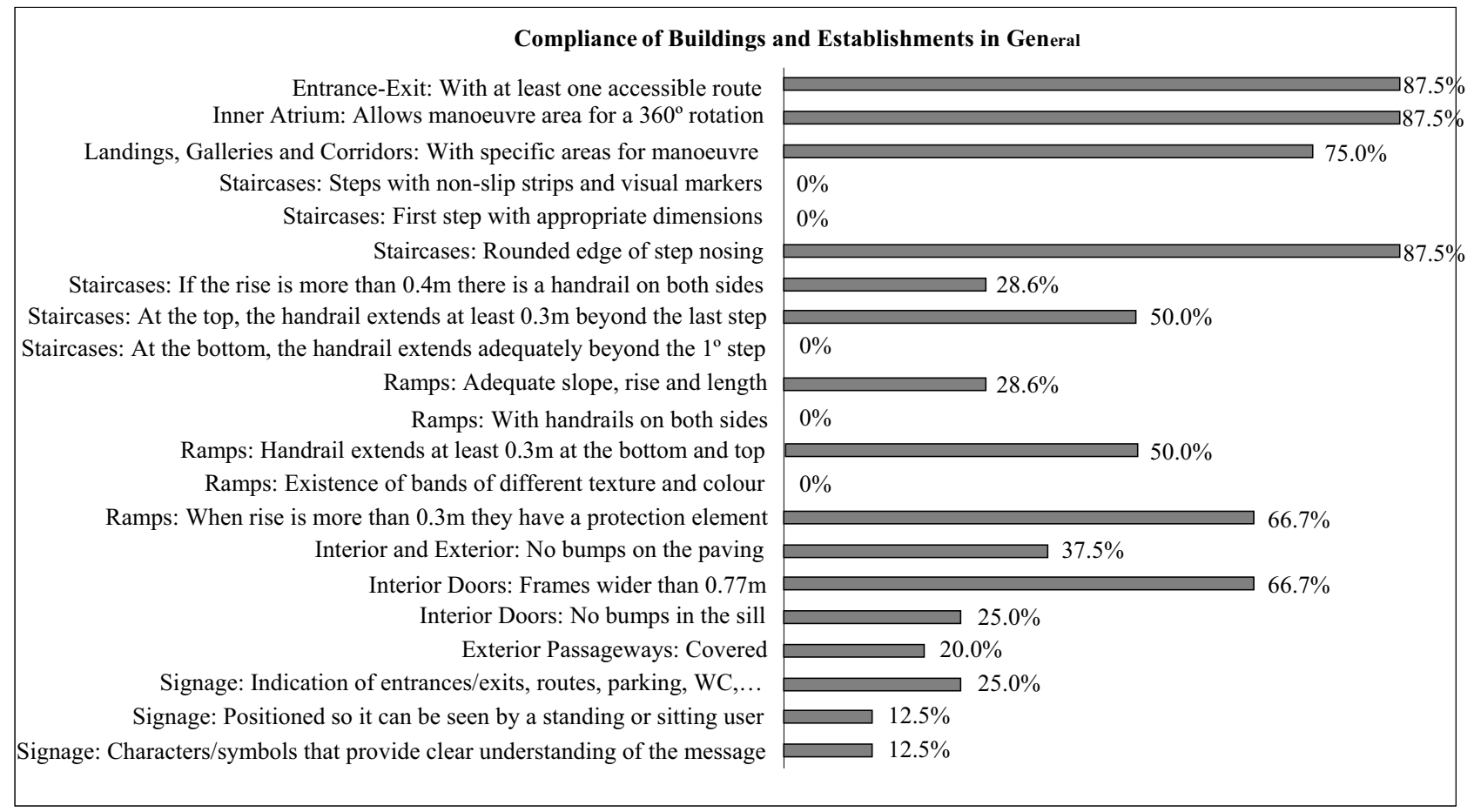

Figure 1 - Characteristics of the buildings and establishments in terms of compliance with the legislation and technical norms. 


\subsubsection{Shower rooms and toilet facilities}

Figure 2 shows the degree of compliance obtained for shower rooms and toilet facilities, in relation to the current legislation.

It was found that in $81.8 \%$ of the cases the doors of toilets/cubicles are sliding or hinged opening outwards; in $90.9 \%$ of the cases they had devices for operating doors at a height of between 0.8 and 1.1 meters, and a distance from the outer edge of the door of no less than 0.05 meters, with doorway widths of no less than 0.77 meters in $72.7 \%$ of the cases.

Regarding the surface of the washbasin, it was found that all the facilities included in the study sample complied with the size and height specified in the legislation, as well as the minimum area required for transferring from the toilet to the wheelchair.

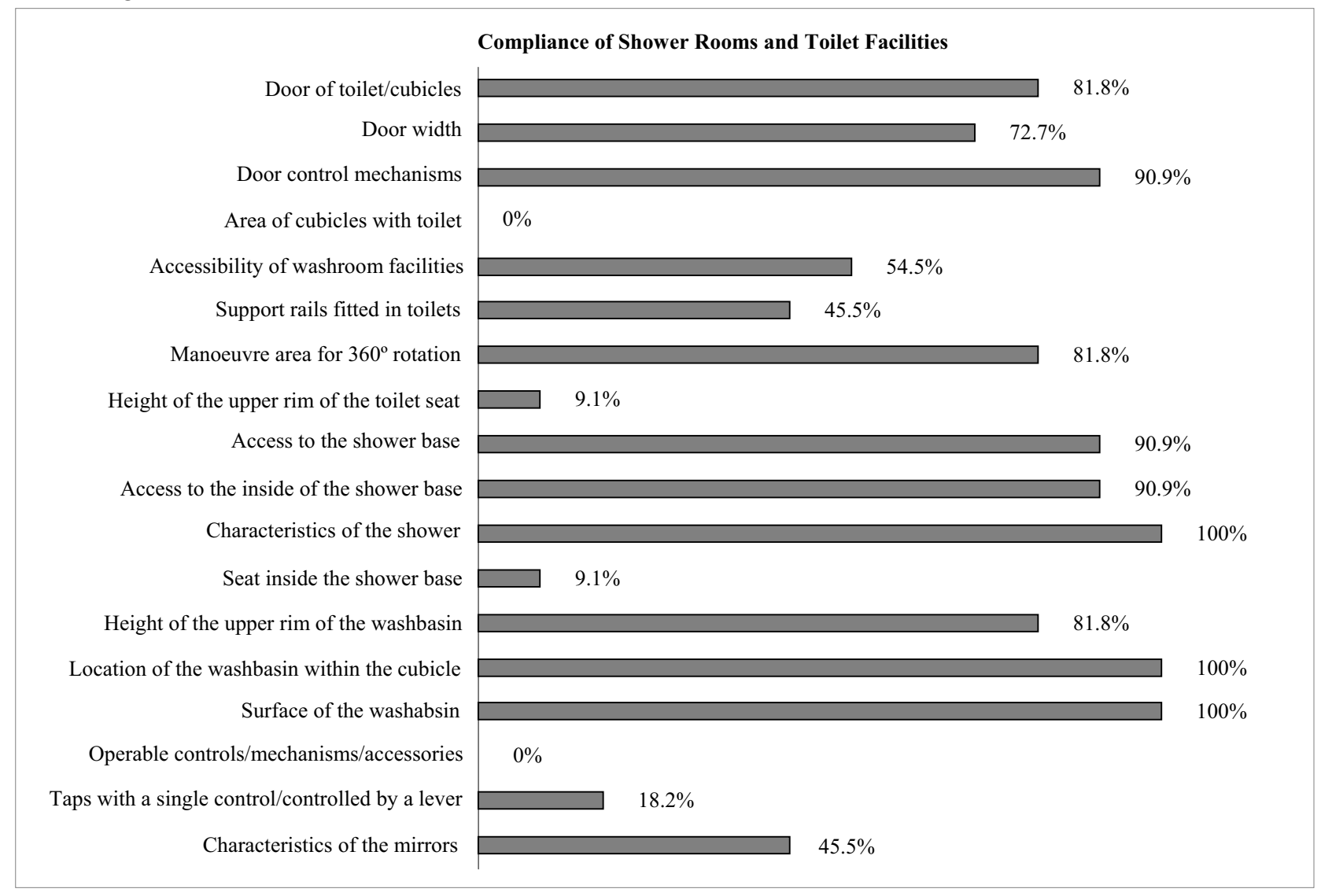

Figure 2 - Characteristics of shower rooms and toilet facilities in terms of compliance with the legislation and technical norms.

It was verified that, for sport facilities where the accessible toilet was in a cubicle, the cubicle dimensions did not meet the minimum dimensions $(2.2 \mathrm{x}$
In terms of operable controls/mechanisms and accessories, it was found that controls for taps, drains, toilet flush valves and accessories, such as towel rails, soap dishes, toilet paper holders, do not meet the requirements of current legislation, in so far as they cannot be operated by a closed hand, they offer minimum resistance, and require a firm hold and rotation of the wrist.

With regards to the characteristics of the mirrors, it was found that in $45.5 \%$ of the cases they are usable by a sitting person and standing person, with the base of the mirror at a height of no more than 0.9 meters from the floor and the upper edge of the mirror at a height no less than 1.8 meters. 
ters $( \pm 0.01$ meters) from the floor. The results further showed that most of the toilets $(54.5 \%)$ did not have removable support rails and, when they were present, they were not at the correct height or the right length required by law.

From the 11 sport facilities, only $1(9.1 \%)$ had showers with a seat inside the base. It was found that this seat had dimensions compliant with the legislation, rounded edges, waterproof and slip-resistant surface, folding and fixed when being used.

\subsubsection{Changing rooms}

In the changing rooms, only $27.3 \%$ of the cases included at least one set of coat hangers/lockers and accessible mirrors for people with reduced mobility and in wheelchairs. None of the changing rooms had fixed seating, although the existing seats were compliant with regulatory dimensions $(0.4 \times 0.8$ meters $)$. However, $18.2 \%$ were not at a height of 0.45 meters ( \pm 0.02 meters) from the floor (Figure 3 ).

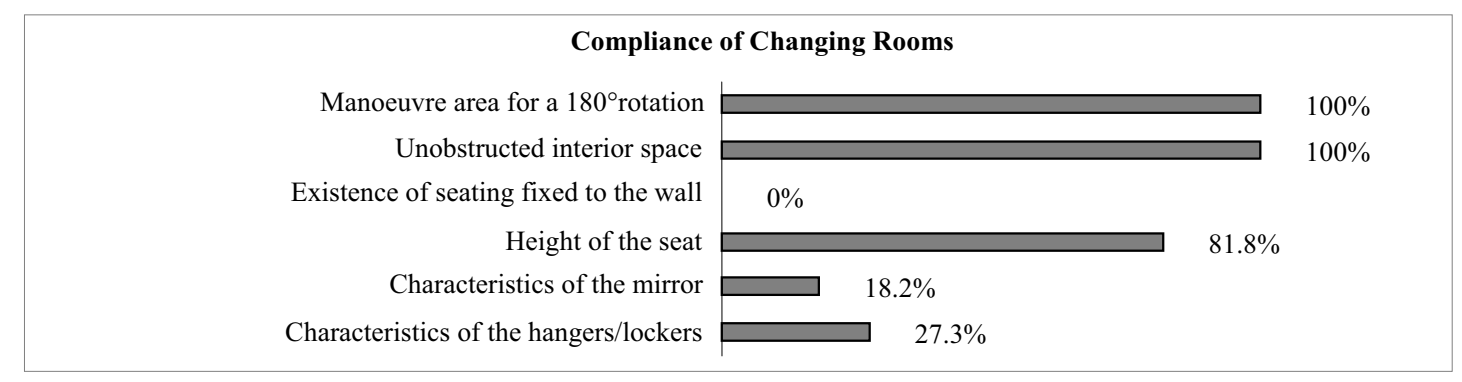

Figure 3 - Characteristics of changing room in terms of compliance with the legislation and technical norms.

\subsubsection{Swimming pools}

On the whole, the pools comply with the regulations. The outside access has an unobstructed entrance with at least one designated accessible route, with a firm and stable surface, no gaps and in good condition. It was found that the inside access of the buildings has sufficient maneuver space for a $360^{\circ}$ rotation; the entrance/exit doors are at least of the minimum width envisaged in the law; doors that access the exterior have metal structures with handles along the entire width, which serve as a safety feature to make them visible. Regarding interior circulation, it was found that the landings and corridors have a minimum width of 1.2 meters, the doorways have a width of no less than 0.77 meters and a height of no less than 2 meters.

In every situation, the devices for operating the doors are at a height of between 0.8 and 1.1 meters from the floor. However, their distance from the outer edge of the door (of no less than $0.05 \mathrm{~m}$ ) is not always observed. The devices for operating the doors offer minimal resistance, they are easy to grab with the hand, and do not require a firm hold or rotation of the wrist.
In relation to the pool tank, the surrounding access, as well as stairs and ramps have an anti-slip coating; the finishing of the edges of the steps and other elements are rounded. Access stairs and ramps have double handrails located at a height of 0.75 and 0.9 meters from the ground. The biggest non-compliance was found in the access to the water: only $50 \%$ of the cases was it done by ramp or mechanically.

\subsection{Results of the questionnaires}

The study sample comprised 24 people with permanent paralysis of the lower extremities (paraplegics), 6 of whom (25\%) also experienced reduced mobility in the upper limbs.

The ages of participants in the sample ranged from 25 to 42 years old (mean age 33; median age 33,5).

All participants were aware of the existence of adapted physical activities. However, of the 24 people who took part, only $2(8 \%)$ had sporting/recreation activities available in the area where they lived, and only 5 (21\%) did some physical activity/sport. The reasons given for the lack of physical activity by the rest of the sample are summarised in Figure 4. 


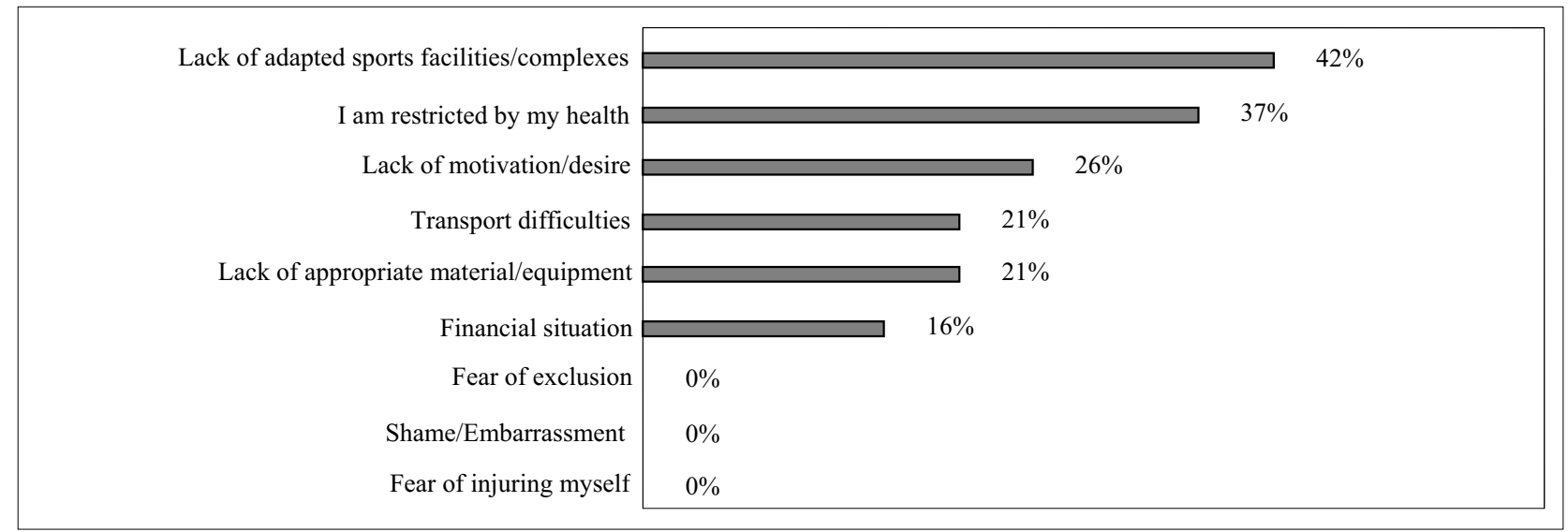

Figure 4 - Reasons why participants did not perform any physical activity (in percentage).

The lack of suitable sports facilities was the most cited reason for not exercising. Nevertheless, all participants felt that physical activity would benefit them (Figure 5). Regarding the benefits of exercising, $75 \%$ of the participants thought general wellbeing as one of the greatest benefits, followed by an improvement in the psychomotor functions $(59 \%)$ and in the physical condition (55\%).

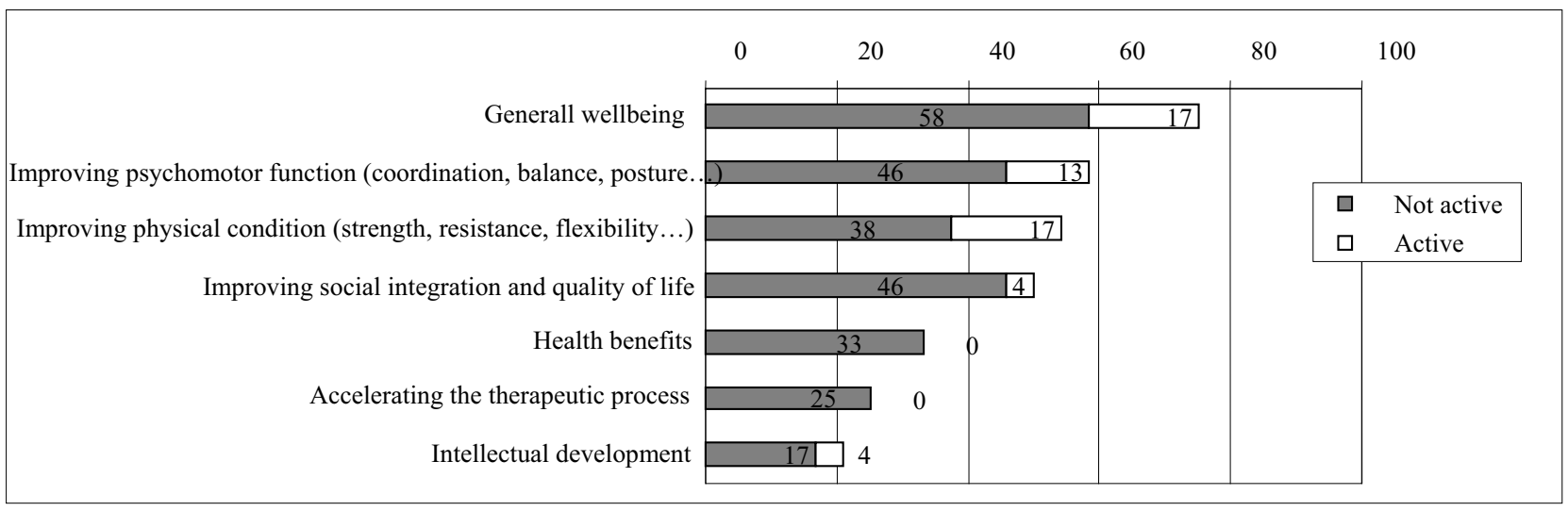

Figure 5 - Benefits of exercise cited by participants (in percentage).

Figure 6 illustrated the reasons why the participants would like to exercise. Once again, general wellbeing was the most cited reason $(63 \%$ of partici- pants), followed by socialising (46\%), keeping busy $(41 \%)$ and getting away from the routine (37\%). 


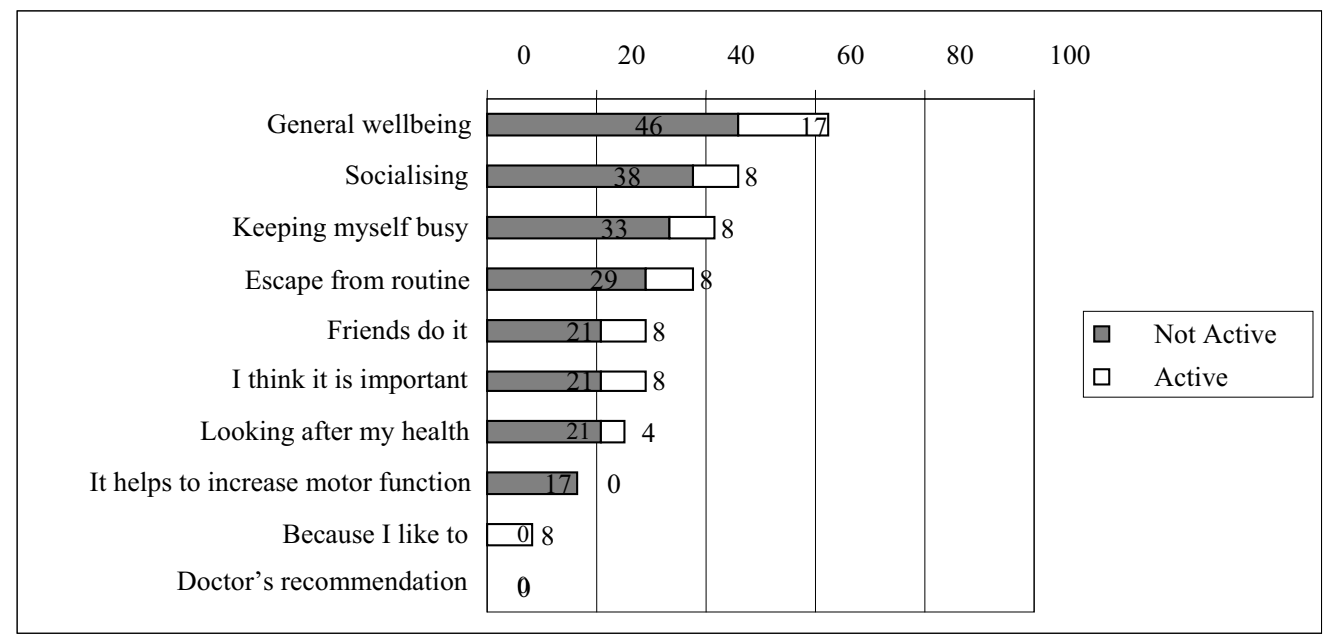

Figure 6 - Reasons for exersising cited by participants (in percentage).

\section{Conclusions}

The non-compliances found in sports facilities compromise the active participation of people with reduced mobility, particularly wheelchair users.

There are several architectural barriers, obstacles that must be eliminated. Since the world of sport has various strands, including therapeutic benefits, applicable to people with reduced mobility, promoting social integration and quality of life, it seems that it is not being properly exploited.

The barriers found give substance to participants' dissatisfaction regarding the lack of adapted sports facilities/complexes. This finding is even more serious when it becomes apparent that the study population recognises various benefits and reasons for physical exercise. Although there is legislation and technical norms that allow people with limited mobility to access all community systems and services, these are not being observed. What is more, the lack of safety for any individual is also evident in some of the sports facilities.

\section{Acknowledgements}

For their participation in this study, the researchers would like to thank the Centro de Reabilitação Profissional de Gaia, Arcozelo, Vila Nova de Gaia; the Clínica de Fisioterapia FISIMAIA, Maia; and the Clínica Médica Arrifana de Sousa, Lda, Penafiel.

\section{References}

[1] Council of Europe Committee of Ministers Recommendation No. R(92) 13REV: European Sports Charter (1992 Revised 2001).

[2] European Scrutiny Committee (2011); Commission Communication: European Disability Strategy 20102020: A Renewed Commitment to a Barrier-Free Europe, 13th Report, 12 January, 83

[3] Ramilo, M.T. (1986). O envelhecimento. ISEF-UTL, Lisboa.

[4] Falcato, J.; Bispo, R. (2006). Design inclusivo Acessibilidade e usabilidade em produtos, serviços e ambientes. Centro Português de Design.

[5] Instituto do Desporto de Portugal, 2008 http://www.idesporto.pt/conteudo.aspx?id=27\&idMenu=4

[6] Conselho da Europa (1988). Carta Europeia do Desporto para Todos: as Pessoas Deficientes (Desporto e Sociedade - Antologia de Textos $n^{0}$ 105). Lisboa: Ministério da Educação, Direcção Geral dos Desportos.

[7] Lei $\mathrm{n}^{\mathrm{o}} 38 / 2004$ de 18 de Agosto Lei de Bases da Prevenção, Habilitação; Reabilitação e Participação das Pessoas com Deficiência. 